\title{
Next-Generation Sequencing and the Return of Results
}

\author{
Bartha Maria Knoppers, ${ }^{1}$ Minh Thu Nguyen, ${ }^{1}$ Karine Sénécal, ${ }^{1}$ Anne Marie Tassé, ${ }^{2}$ \\ and Ma'n H. Zawati ${ }^{1}$ \\ ${ }^{1}$ Centre of Genomics and Policy, McGill University, Montreal, Quebec H3A 0G1, Canada \\ ${ }^{2}$ Public Population Project in Genomics and Society $\left(\mathrm{P}^{3} \mathrm{G}\right)$, Montreal, Quebec H3A 0G1, Canada \\ Correspondence: man.zawati@mcgill.ca
}

\begin{abstract}
The impact of next-generation sequencing (NGS) on the issue of return of results is defying clear policy guidance and creating international confusion. Limiting ourselves to the return of results revealed by NGS (including incidental findings) in adults, children, family members of deceased individuals, and population studies, we describe and contrast emerging policy positions in Europe, Canada, and the United States. Until there are clear, scientific, and professional standards and practical policy, both researchers and clinicians cannot be faulted for being either hesitant or pressured to return NGS results.
\end{abstract}

In n 2006, our analysis of international policy guidance revealed the gradual emergence of an ethical duty to disclose genetic results, particularly in the field of biomedical research (Knoppers et al. 2006). Research by its very nature seeks to provide generalizable knowledge, not clinical, individually identifiable results. Yet, with next-generation sequencing (NGS) entering the research domain, this affirmation loses its salience because of the massive amounts of information it generates (Wolf et al. 2008). When NGS is used in medical genetics, the potential for discovering health-related findings of clinical significance to patients and research participants is becoming ever more prevalent (Cho 2008). The issue of how to handle these findings is not only topical, but also increasingly challenging for both clinicians and researchers. The conclusions of the 2006 article cited below may, however, have been somewhat prescient of this "next-generation" future, the multitude of findings using whole-genome/exome sequencing potentially transforming research participants into patients and researchers into "potential" clinicians (Knoppers et al. 2006):

Resolution of the question of whether there is a duty to return global or individual genetic research results depends on the type of study, the clinical significance and reliability of the information, and whether the study involves patients, genetically "at-risk" families for a tested predisposition or healthy volunteers. Further confounding the emerging duty to return genetic research results is the situation in which the researcher is also a clinician and the participant is also a patient.

Already in 2009, the Organization for Economic Co-operation and Development (OECD) was

Editors: W. Richard McCombie, Elaine R. Mardis, James A. Knowles, and John D. McPherson

Additional Perspectives on Next-Generation Sequencing in Medicine available at www.perspectivesinmedicine.org

Copyright (C) 2016 Cold Spring Harbor Laboratory Press; all rights reserved; doi: 10.1101/cshperspect.a026724

Cite this article as Cold Spring Harb Perspect Med 2016;6:a026724 
B.M. Knoppers et al.

circumspect about the need for choice surrounding the return of results. It maintained that in the context of population biobanks, genetic research databases "should provide clear information to the participant of the consequences of receiving such results and should inform the participant of their right to opt out from receiving such results. Nonvalidated results from scientific research using $\mathrm{Hu}$ man Biobanks and Genetic Research Database (HBGRD) human biological materials, and data should not be reported back to the participants and this should be explained to them during the consent process" (OECD 2009). Of particular importance is this latter cautionary note concerning nonvalidated results.

In 2013, the Declaration of Helsinki addressed the issue of return of results in a broad manner. It held that: "All medical research subjects should be given the option of being informed about the general outcomes and results of the study" (see WMA 2013). Thus, just as in the OECD's position cited above, and in conformity with both the position of UNESCO (2003) and that of the Convention on Human Rights and Biomedicine (hereafter Oviedo Convention) of the Council of Europe (1997), it recognizes the right "not to know." Indeed, in 1997, the Oviedo Convention stated: "Everyone is entitled to know any information collected about his or her health. However, the wishes of individuals not to be so informed shall be observed" (Chapter III, Article 10.2). This is a logical corollary of the right to know, but became particularly important at the end of the 1990s as the implications of the Human Genome Project were being studied (Knoppers 2014).

Other international policies also uphold the need to provide a nuanced approach to the return of results. Indeed, also in 2013, the Public Population Project in Genomics and Society $\left(\mathrm{P}^{3} \mathrm{G}\right)$ warned against automatic return of results, especially in population studies in which citizens contribute samples and data to an infrastructure for future unspecified biomedical research (Knoppers et al. 2012b). Likewise, the European Society of Human Genetics (ESHG) (Hens et al. 2013) recognizes the possibility of not only such a "no return" policy for biobanks (in contrast to clinical trials involving patients), but also reinforces the duty to provide an option for adults if there is a follow-up diagnostic test for validation.

Finally, our 2015 review of return of results legislation and policies revealed that four different approaches are generally used internationally for the return of results: (1) only panels of specific genes or targeted sequencing are allowed, to reduce the potential for incidental findings (although this not always explicitly stated as such); (2) results can only be returned when they meet the following criteria: analytical validity, clinical significance, and actionability; (3) an ad hoc case-by-case determination; and (4) no return (Knoppers et al. 2015). Recently, the 2016 ESHG Guidelines for Diagnostic Next-Generation Sequencing maintain that gene panels should preferably be offered, and the analysis pipeline should focus on the gene panel under investigation to avoid the chance of secondary findings. If a clinical center or a laboratory decides to offer patients an opt-in or opt-out protocol to get carrier status for unrelated diseases and secondary findings, all the logistics need to be covered (including pretest genetic counseling) (ESHG 2016). The Council of Europe's Recommendations on Research on Biological Materials of Human Origin does not mention NGS but does recommend that researchers have in place a feedback policy (Council of Europe 2016).

This review then covers the spectrum of positions on the return of results and its implications from adults, to children, family members of deceased individuals, and finally population studies. Relying chiefly on policy positions and consensus statements, it illustrates a relentless move toward the disclosure of both research results and incidental findings. This is bolstered by "client" demand and professional abdication in face of the difficulty in distinguishing what information is incidental. For the purpose of simplicity, we will use the term "results" as including incidental findings unless the sources cited do otherwise. 


\section{ADULTS}

Notwithstanding inherent and obvious differences between research and clinical care, and cognizant of the fact that physicians have clear ethical and legal duties to their patients, each setting is faced with similar issues relating to the return of NGS results in adult populations. This section on return of results to adults will highlight a number of these issues as well as the main trends that are particular to clinical care and research, respectively.

In the clinical care setting, recommendations surrounding the use of NGS in adult populations focus mainly on counseling and on the management of return of results. For example, in its 2013 Recommendations on Reporting of Incidental Findings in Clinical Exome and Genome Sequencing, the American College of Medical Genetics and Genomics (ACMG) called for the implementation of pretest counseling sessions, during which medical professionals would discuss the expected outcomes of testing and the type of results that would or would not be returned to patients or their representatives (Green et al. 2013). These same recommendations also emphasized that it is the responsibility of the ordering clinician/team to provide comprehensive posttest counseling to patients (Green et al. 2013). In dealing with difficult posttest communications, the U.S. Presidential Commission's 2013 Report on the Ethical Management of Incidental and Secondary Findings in the Clinical, Research, and Direct-to-Consumer Context recommends that clinicians consider "providing patients with decision aids and graphical representations, using populationbased evidence, and describing a patient's absolute risk: " . . rather than or in addition to relative risk” (Presidential Commission 2013).

Also in 2013, the ACMG stated that, in the context of NGS, physicians have a mandatory duty to disclose incidental findings and provides a list of 56 medically "actionable" genes (Green et al. 2013). Given the fact that, as we have just seen above, normative documents on the return of results routinely acknowledged the importance of respecting patient preferences (including the right to refuse information relat- ing to incidental or secondary findings), this ACMG position was controversial. Following a yearlong debate, the ACMG Board voted in 2014 to refine its policy, and recommended that "... an opt-out option be offered to patients who are considered candidates for clinical genome-scale sequencing" (ACMG 2014). This position has been retained in the 2015 ACMG Policy Statement, Updated Recommendations Regarding Analysis and Reporting of Secondary Findings in Clinical Genome-Scale Sequencing, which states "... regardless of the specific indication for testing, laboratories will routinely analyze the sequence of a set of genes deemed to be highly medically actionable so as to detect pathogenic variants that may predispose to a severe but preventable outcome. Patients should be informed during the consent process that, if desired, they may opt out of such analysis...." On that point, recent recommendations provide that "... investigators are not obligated to search for actionable genomic variants to be returned beyond those identified in the course of their research" (Jarvik et al. 2014).

In contrast, the ESHG recommended that laboratories filter results to avoid clinical incidental findings (ESHG 2016). It also called for the development of guidelines concerning informed consent and the effect of professional responsibilities on the patients' right not to know (Van El et al. 2013).

Existing normative documents are largely silent on the issue of return of results for adults who lack the capacity to consent. A Canadian proposal for reporting results from whole-genome and whole-exome sequencing in clinical practice in Canada (Zawati et al. 2014) highlighted three important factors to consider when returning results to incompetent adults or their legal representatives: (1) Decisions regarding incapable adults should be made in their best interests; (2) incompetent adults have the right to participate in the decisionmaking process as much as is practically possible; and (3) legal representatives cannot opt out of receiving results that reveal the existence of a clinically significant and actionable condition (Zawati et al. 2014). For its part, the Canadian College of Medical Geneticists emphasizes that 
results revealing a highly penetrant medically actionable condition should be reported to the legal representative, unless the incompetent adult concerned expressed wishes to the contrary while still competent (CCMG 2015).

Turning now to the research setting, policies relating to the return of results for adults have focused on three distinct stages: (1) prestudy planning; (2) the consent process; and (3) poststudy communication of findings.

For example, the Canadian Tri-Council Policy Statement: Ethical Conduct for Research Involving Humans (TCPS2) requires that researchers "develop a plan indicating how they will disclose [research]... findings to participants, and submit this plan to the Research Ethics Board (IRB)" (CIHR 2014). Similarly, the U.K.'s Medical Research Council and Wellcome Trust's Framework, in 2014, states that researchers are expected to "... have a policy that indicates whether or not HRFs (health-related findings) will be fed back to individuals that can be clearly articulated, and be able to show the reasoning behind their policy to research participants, funders and the Research Ethics Committee" (MRC and Wellcome Trust 2014). The Presidential Commission (2013) issued a similar recommendation in its 2013 report.

The Quebec Network of Applied Medical Genetics (RMGA) Consolidated Statement of Principles recommend that, where researchers plan to share findings with individuals, the researchers should allow participants to make an informed choice as to the return of results (RMGA and GCP 2016). This recommendation is in accordance with the TCPS2 requirement that researchers provide participants with the opportunity "make informed choices about whether they wish to receive information about themselves" (CIHR 2014). The U.S. Presidential Commission's report provides a more detailed recommendation on this matter, and as such requires that researchers convey to "participants the scope of potential incidental or secondary findings, whether such findings will be disclosed, the process for disclosing these findings, and whether and how participants might opt out of receiving certain types of findings" (Presidential Commission 2013).
Policymakers have yet to reach a consensus on the best and most effective way to return research results to participants. Whereas in the United Kingdom, the Medical Research Council and Wellcome Trust (CIHR 2014) advocate a "context-specific" approach to feedback, the Canadian TCPS2 requires that feedback be provided where findings have been interpreted as having serious welfare implications for participants, unless the researcher had requested and obtained the REB approval for a waiver of the obligation to disclose material incidental findings to the participant, based on impracticability or impossibility (CIHR 2014).

Expert consultations are recommended (Presidential Commission 2013; CIHR 2014), as are sessions with genetic counsellors (CIHR 2014). Quebec's RMGA Consolidated Statement of Principles of 2016 adopts a more detailed and nuanced approach, recommending that individual research results and incidental findings be returned where (1) they satisfy the generally accepted criteria of clinical usage and scientific and clinical validity; (2) exceptions and considerations relating to research have been appropriately weighed; (3) REB approval has been obtained; (4) participants have opted to receive such findings; and (5) the research result has been confirmed by an accredited laboratory before being returned to the participants. This same statement recommends that such results be returned to legal representatives in research involving incompetent adults (RMGA 2016). It should be noted that each jurisdiction has their own system of quality assurance and certification regarding the accreditation of laboratories (e.g., the United States has CAP/CLIA).

As shown, although policy makers have endeavored to clarify when and if results should be returned to patients and/or research participants, there are still a number of controversies. These include the requirement to return medically actionable results whether in research or clinical contexts within the confines of local laboratory reporting requirements. This is of particular importance in the pediatric context where issues regarding the return of results are more complicated. 


\section{PEDIATRICS}

Issues that arise in the genetic testing of adults are also applicable in the context of genetic testing of minors. However, there are certain distinctions that are particular to the field of pediatrics. Traditionally, pediatric ethics is framed by the promotion and protection of the best interests of the child. This beneficence-based standard often recognizes the child's "right to an open future" (Bredenoord 2013) and encourages limiting the use of genetic testing to clinically relevant and actionable results during childhood. Clinical guidelines typically advocate that testing in minors only be recommended when established, effective, and important medical treatment can be offered or when preventive measures exist (Borry et al. 2006). This is the case regarding predictive genetic testing of minors for adult-onset diseases and carrier status (ASHG 2015). The rationale behind this position is that genetic testing in these cases should be delayed until the child is old enough to make an informed choice.

In contrast to adult genetic testing, pediatric genetic testing also requires that parents act as surrogate decision-makers until the child reaches the age of majority. This results in possible tensions between (1) the respect for parental authority, (2) respect for the child's future autonomy, and (3) the potential benefit and harm of the information to the parents, siblings, and other biological relatives. Thus, complex issues in returning genetic results are magnified when dealing with minors.

Genomic information derived from NGS is already being used to help identify the genetic component of common health problems or complex phenotypes (Tabor et al. 2011; Downing et al. 2012; Gahl et al. 2012). In the clinic, NGS is used in pediatrics to establish a diagnosis for a sick child (Goh et al. 2012) to exclude the possibility of a rare genetic disorder, to find the gene responsible for an unknown syndrome to identify and anticipate future health problems (Amor 2015) or to increase the precision of medical prescriptions (Bainbridge et al. 2011; Hawcutt et al. 2013; Steven et al. 2013). In addition, NGS is becoming a centerpiece in inter- national pediatric research (e.g., Children's Oncology Group). NGS could one day also play a role in public health through newborn screening programs (Knoppers et al. 2014) or personalized screening for common cancers, adopting a population-based genotyping approach (Hall et al. 2014).

Although there is much evidence supporting its usage, NGS poses challenges to traditional pediatric ethical and legal norms. With NGS, an enormous amount of health data is revealed concerning the future health of the child. This, in turn, challenges and intensifies the debates surrounding the clinical usage of the information, policies regarding the return of results, informed consent and assent procedures, the right of parents to know (or not to know), and the child's "right" to an open future. Primarily, how should the best interests of the child standard be applied in the era of NGS in pediatrics? There are very few guidelines that address this particular question.

In 2014, the $\mathrm{P}^{3} \mathrm{G}$ International Pediatrics Platform advocated that NGS results, obtained in a research context, that are scientifically valid, clinically useful, and reveal conditions that are preventable and actionable during childhood should be reported to parents (Knoppers et al. 2014). Moreover, mutations that predispose the child to develop an adult-onset disorder, even if accidentally discovered, generally should not be returned (Knoppers et al. 2014). This allows the child to make his or her own decision about receiving the results as an adult. However, when such findings also concern the health of family members, some exceptions to the general principle are possible (Knoppers et al. 2014).

In the clinical setting, the ESHG recommendations urge caution over the use of NGS for minors. As mentioned above, the 2016 ESHG Guidelines for diagnostic next-generation sequencing state that the analysis pipeline of diagnostic laboratories should focus on the genes panel under investigation to avoid the chance of secondary findings (ESHG 2016). This general statement, although not specific to the use of NGS in the pediatric population, goes in the same line as previous ESHG guidelines that propose that analysis should be limited to genome 
B.M. Knoppers et al.

regions linked to the clinical problem for which the analysis is undertaken (Van El et al. 2013):

In the case of testing minors, guidelines need to be established as to what unsolicited information should be disclosed to balance the autonomy and interests of the child and the parental rights and needs (not) to receive information that may be in the interest of their (future) family.

The ACMG had adopted two different sets of recommendations regarding the genetic testing and screening of children. The first recommendation, adopted jointly with the American Academy of Pediatrics (AAP) in February 2013, reaffirmed that diagnostic genetic testing should be driven by the best interests of the child and that carrier screening and presymptomatic testing of children at risk for adult-onset diseases should generally be deferred until maturity (ACMG and APP 2013). Accordingly, testing for adult-onset diseases in children would only be allowed in rare and exceptional cases in which there would be a benefit to the child or the family members. A month after adopting this first set of recommendations, the ACMG endorsed, in March 2013, a statement addressed to both clinicians and laboratories regarding the use of secondary results obtained from NGS in adults and children. In this March 2013 statement, the ACMG stipulated that clinical laboratories should actively search for 56 genes associated with pathogenic mutations (that can be prevented and treated) and report these results to ordering clinicians, regardless of the patient's age and regardless of whether the patients consented to receiving such results (Green et al. 2013). In a subsequent clarification statement in 2013, the ACMG reaffirmed its position regarding not testing minors for adult-onset diseases but added that incidental findings of "severe, actionable, pathogenic mutations" should be communicated to parents. However, in 2014 (as noted in the above section on adults), the ACMG's Board voted to provide patients with an opt-out of such NGS testing. Peculiarly, the subsequent 2015 ACMG Policy Statement, Updated Recommendations Regarding Analysis and Reporting of Secondary
Findings in Clinical Genome-Scale Sequencing (ACMG 2015) clearly stipulates that

Clearly, the 2015 ACMG updated recommendations do not make a distinction between adult and pediatric patients, although the results that can be returned to parents/legal guardians of children may concern pathogenic variants in genes associated with adult onset conditions. Parents can potentially opt out of receiving results that are medically actionable during childhood (ACMG 2015). This stands in contrast to a recent policy consensus of the American Society of Human Genetics, which mandates return of medically actionable results in childhood. In addition, the ACMG position is also very different to that of the CCMG (2015). In its Position Statement of the Canadian College of Medical Geneticists (CCMG) concerning the clinical application of genome-wide sequencing for monogenic diseases in Canada, the CCMG recommends that, in children, incidental results that reveal risks for a highly penetrant condition that is medically actionable during childhood should be reported to the parents. A child's risk for adult-onset genetic conditions should not be communicated unless (1) the parents request such disclosure, and (2) disclosure of the information could prevent serious harm to the health of a parent or family member, as determined on a case-by-case basis (CCMG 2015).

Hence, a limited obligation to disclose certain actionable results to parents is emerging. Parents have an obligation to provide medical care for their children under child protection legislation, irrespective of their personal views, religion, or lifestyle. Moreover, given the inability of children to provide informed consent, parents are obliged to receive results based on the parental obligation to act in their child's best interests. 


\section{FAMILY MEMBERS OF DECEASED INDIVIDUALS}

Almost two decades ago, the HUGO Ethics Committee considered family as the nexus of a variety of relationships, and stated that when family members are at risk of having a genetic disorder, and when prevention or treatment is available, special consideration should be given to the disclosure of genetic information to immediate relatives. Failure to provide access to genetic information after death could affect the interest of present and future relatives (HUGO 1998).

However, the return of NGS results from a deceased person raises numerous ethical and legal issues and requires weighing the competing rights and interests of the deceased individual with those of family members (OECD 2009). The sensitive nature of genetic information, the time elapsed since death, the expressed wishes of the deceased to disclose the results (or not), the family members' wishes to receive them (or not), and the relevance of the results for the health of living relatives must all be considered (Tassé 2011; Bredenoord 2012; Chan et al. 2012; Boers 2015).

Although some international guidelines foresee a potential conflict between (1) respecting the confidentiality and privacy of the data subject, and (2) providing third parties with potentially meaningful health information (WMA 2002, 2006; WHO 2003), most guidelines state that identifiable human genetic data and biological samples should not be disclosed or made accessible to third parties, including family members, without prior consent (CIOMS 2008). These guidelines do not specifically address the case of deceased data subjects, but they allow the disclosure of personal health information, when provided for by domestic laws (UNESCO 2003, 2005; OECD 2009).

Few domestic laws govern the disclosure of genetic information contained in the medical record of deceased individuals. For example, Quebec's Act Respecting Health Services and Social Services mentions that “. . . persons related by blood to a deceased user may be given communication of information contained in his re- cord to the extent that such communication is necessary to verify the existence of a genetic or hereditary disease." However, in other jurisdictions, disclosing NGS results to family members may violate privacy laws (Rothstein 2012).

Regarding the disclosure of research results, a consensus seems to emerge from the literature (Tassé 2011; Bredenoord 2012; Boers 2015) and guidelines, that genetic research results from a deceased participant could be returned to family members if (RMGA 2016)

1) they meet generally accepted criteria of scientific and clinical validity;

2) they have significant implications for family members;

3) the participant has previously consented that they be transmitted to family members;

4) REB approval has been obtained;

5) the family (i.e., the persons directly affected by the results) have consented; and

6) the research result has been confirmed.

In the particular context of NGS, these criteria substantially reduce the extent of information that may be returned, because only research results having significant health implications for family members could be disclosed.

\section{POPULATION STUDIES}

The building of population studies (biobanks) that are longitudinal in nature and that follow the data and samples of citizens in real time in their socio-demographic contexts is a relatively new concept-infrastructure science supporting discovery science (Schofield et al. 2010). Expensive to set up and maintain, as well as difficult to explain to ethics committees acquainted as they are with clinical trials and interventionist research, the goal is to follow largely asymptomatic cohorts over time and that are representative of the population as a whole, so as to discern trends in disease and health (Knoppers et al. 2014).

In population research, questionnaires and the taking of blood samples are often called "assessments" or "measurements" and are not to be confused with medical care. Participants are "information altruists" (Kohane et al. 
B.M. Knoppers et al.

2005), often enrolled under a no-return of results policy. Although feedback on some basic measurements and critical values at the time of assessment or the finding of immediate lifethreatening conditions are exceptions to this no-return rule, recontact is only foreseen for updates of questionnaires, new measurements, or for participation in other projects by outside researchers wishing to access these biobanks. On the whole, one exception to the noreturn policy are those biobanks built using samples and data obtained during medical care with recruitment led by physicians in the context of a clinical relationship. Another exception is the add-on currently piloted in some population biobanks, in which a set of already enrolled participants are invited to partake in new measurements that include magnetic resonance imaging (MRI). In the new consent, these participants are informed that certain severe structural abnormalities will be returned to them and provided to a physician of their choice, if they so wish.

Communication of aggregate results is offered to participants via newsletters and websites. Moreover, researchers using the biobank database are asked to return their results to the database to enrich its quality but, generally, not to communicate directly with participants. Usually, all communication concerning possible participation in additional studies is handled by the biobanks themselves out of fear of both over-solicitation and possible attrition (Knoppers et al. 2012a).

The possible effect of outside access and use by researchers on this no-return policy was not, however, addressed by most biobanks. Today, these population cohorts are being approached by disease-specific studies, for example, for "enhancement" studies using MRIs, as mentioned above. Population studies are also being faced with requests for access by researchers whose research projects use NGS with its attendant incidental findings. Thus, like in MRI studies, there is now increasing pressure to inform cohort participants of such findings when they are medically actionable (i.e., prevention or treatment is available) (Knoppers and Laberge 2009).
In short, there is potential for wide variability concerning the return of results in the context of research using NGS that accesses population studies. Although most biobanks prefer to communicate directly with their own participants, the possibility of including a family physician in the communication of the results if the biobanks do not want to assume this responsibility or are not trained to do so (with the exception of clinical biobanks) can have the necessary support. But general physicians may also not be versed in the language of alleles, of rare diseases, and in the uncertain scientific validity and clinical usage of sequencing results (whether it goes through a CLIA-certified laboratory [in the United States] or not).

\section{CONCLUSION}

NGS is creating the blending of the clinical and research domains, of adults and children, of population studies, families and individuals, and of the living and the deceased. The wealth of data it provides can and will be translated into knowledge over time as well as backward and forward in time. Currently, researchers find themselves looking at results they do not know how to interpret, because it is outside of their protocol, and clinicians will turn to researchers for interpretation of NGS results for as yet undiagnosed etiologies. Hence, although this article has been divided along traditional categories of professional norms that guide research and clinical care involving adults, children, family members of deceased individuals, and population studies, our analysis of the norms reveals this slow but certain coalescing. In the interim, although epidemiologists decide between binning or filtering of NGS results for scientific validity (Berg et al. 2011), or in the case of filtering, decide to stay within a limited range of findings, geneticists are creating information technology (IT) tools and primers for diagnosis NGS (Biesecker and Green 2014). The NGS normative landscape is murky indeed. One thing is certain, however-researchers will increasingly find themselves measured against traditional medical "duties" unless systemic changes, such as oversight boards (Holm et al. 2014), are made 
Next-Generation Sequencing and Return of Results

to relieve them of such misaligned duties. Moreover, professional norms on the return of results will also need to go beyond scientific criteria and factor in the socio-ethical and legal issues because the community fallout from NGS potentially overshadows all other uncertainties (Jarvik et al. 2014).

\section{ACKNOWLEDGMENTS}

This work is supported by Génome Québec, the Quebec Network of Applied Genetic Medicine of the Fonds de Recherche du Québec, the Ministère de l'Économie de la Science et de l'Innovation du Québec (PSR-SIIRI-850), and the Canadian Partnership against Cancer (CPAC). The authors thank Shuang and Vassilis Ragoussis for their assistance in the preparation of this manuscript.

\section{REFERENCES}

ACMG and AAP. 2013. Ethical and policy issues in genetic testing and screening of children. Pediatrics 131: 620622.

ACMG. 2014. Updates to the ACMG's Recommendations of reporting of incidental findings in clinical exome and genome sequencing, 2014. acmg.net/docs/Release_AC MGUpdates-Recommendations_final.pdf

ACMG. 2015. ACMG Policy Statement: Updated recommendations regarding analysis and reporting of secondary findings in clinical genome-scale sequencing. Genet Med 17: 68-69.

ASHG. 2015. Points to consider: Ethical, legal, and psychosocial implications of genetic testing in children and adolescents. Am J Hum Genet 97: 6-21.

Amor DJ. 2015. Future of whole genome sequencing. J Paediatr Child Health 51: 251-254.

Bainbridge MN, Wiszniewski W, Murdock DR, Friedman J, Gonzaga-Jauregui C, Newsham I, Reid JG, Fink JK, Morgan MB, Gingras MC, et al. 2011. Whole-genome sequencing for optimized patient management. Sci Transl Med 3: 87re3.

Berg JS, Evans JP, Leigh MW, Omran H, Bizon C, Mane K, Knowles MR, Weck KE, Zariwala MA. 2011. Next generation massively parallel sequencing of targeted exomes to identify genetic mutations in primary ciliary dyskinesia: Implications for application to clinical testing. Genet Med 13: $218-229$.

Biesecker LG, Green RC. 2014. Diagnostic clinical genome and exome sequencing. N Engl J Med 370: 2418-2425.

Boers SN, van Delden JM, Knoers NV, Bredenoord AL. 2015. Postmortem disclosure of genetic information to family members: Active or passive? Trends Mol Med 21: $148-153$.
Borry P, Stultiens L, Nys H, Cassiman JJ, Dierickx K. 2006. Presymptomatic and predictive genetic testing in minors: A systematic review of guidelines and position papers. Clin Genet 70: 374-381.

Bredenoord AL, van Delden JM. 2012. Disclosing individual genetic research results to deceased participants' relatives by means of a qualified disclosure policy. Am J Bioeth 12: $10-12$.

Bredenoord AL, de Vries MC, van Delden JM. 2013. Nextgeneration sequencing: Does the next generation still have a right to an open future? Nature 14: 2.

CCMG. 2015. Position statement: The clinical application of genome-wide sequencing for monogenic diseases in Canada: Position statement of the Canadian College of Medical Geneticists. J Med Genet 52: 431-437.

Chan B, Facio FM, Eidem H, Hull SC, Biesecker LG, Berkman BE. 2012. Genomic inheritances: Disclosing individual research results from whole-exome sequencing to deceased participants' relatives. Am J Bioeth 12: 1-8.

Cho MK. 2008. Understanding incidental findings in the context of genetics and genomics. J Law Med Ethics 36: 280-285.

CIHR (Canadian Institutes of Health Research). 2014. Natural Sciences and Engineering Research Council of Canada, Social Sciences and Humanities Research Council of Canada. Tri-council Policy Statement (TCPS2): Ethical conduct for research involving humans, 2nd ed. CIHR, Ottawa. pre.ethics.gc.ca/pdf/eng/tcps2-2014/TCPS_ 2_FINAL_Web.pdf.

CIOMS (Council for International Organizations of Medical Sciences) and WHO (World Health Organization). 2008. International ethical guidelines for epidemiological studies. WHO, Geneva.

Council of Europe. 2016. Convention for the Protection of Human Rights and Dignity of the Human Being with Regard to the Application of Biology and Medicine: Convention on Human Rights and Biomedicine, 1997; and Recommendation CM/Rec. 2016.6 of the Committee of Ministers to member states on research on biological materials of human origin. coe.int/cm/Pages/result_ details.aspx?ObjectId=090000168064e8ff.

Downing JR, Wilson RK, Zhang J, Mardis ER, Pui CH, Ding L, Ley TJ, Evans WE. 2012. The Pediatric Cancer Genome Project. Nat Genet 44: 619-622.

ESHG. 2016. Guidelines for diagnostic next-generation sequencing. Eur J Hum Genet 24: 2-5.

Gahl WA, Markello TC, Toro C, Fajardo KF, Sincan M, Gill F, Carlson-Donohoe H, Gropman A, Pierson TM, Golas G, et al. 2012. The National Institutes of health undiagnosed disease program: Insights into rare diseases. Genet Med 14: $51-59$.

Goh V, Helbling D, Biank V, Jarzembowski J, Dimmock D. 2012. Next-generation sequencing facilitates the diagnosis in a child with twinkle mutations causing cholestatic liver failure. J Pediatr Gastroenterol Nutr 54: 291-294.

Green RC, Berg JS, Grody WW, Kalia SS, Korf BR, Martin CL, McGuire AL, Nussbaum RL, O’Daniel JM, Ormond $\mathrm{KE}$, et al. 2013. ACMG recommendations for reporting of incidental findings in clinical exome and genome sequencing. Genet Med 15: 565-574.

Hall AE, Chowdhury S, Pashayan N, Hallowell N, Pharoah P, Burton H. 2014. What ethical and legal principles should 
B.M. Knoppers et al.

guide the genotyping of children as part of a personalised screening programme for common cancer? J Law Med Ethics 40: 163-167.

Hawcutt DB, Thompson B, Smyth RL, Pirmohamed M. 2013. Paediatric pharmacogenomics: An overview. Arch Dis Child 98: 232-237.

Hens K, Van El CE, Borry P, Cambon-Thomsen A, Cornel MC, Forzano F, Lucassen A, Patch C, Tranebjaerg L, Vermeulen E, et al. 2013. Developing a policy for paediatric biobanks: Principles for good practice. Eur J Hum Genet 21: $2-7$.

Holm IA, Savage SK, Green RC, Juengst E, McGuire A, Kornetsky S, Brewster SJ, Joffe S, Taylor P. 2014. Guidelines for return of research results from pediatric genomic studies: Deliberations of the Boston Children's Hospital Gene Partnership Informed Cohort Oversight Board. Genet Med 16: 547-552.

HUGO (Human Genome Organization Ethics Committee). 1998. Statement on DNA sampling: Control and access, 1998. hugo-international.org/Resources/Documents/CE LS_Statement-DNASampling_1998.pdf.

Jarvik GP, Amendola LM, Berg JS, Brothers K, Clayton EW, Chung W, Evans BJ, Evans JP, Fullerton SM, Gallego CJ, et al. 2014. Return of genomic results to research participants: The floor, the ceiling, and the choices in between. Am J Hum Genet 94: 818-826.

Knoppers BM. 2014. From the right to know to the right not to know. J Law Med Ethics 42: 6-10.

Knoppers BM, Laberge CM. 2009. Return of "accurate" and "actionable" results: Yes! Am J Bioeth 9: 107-109.

Knoppers BM, Joly Y, Simard J, Durocher F. 2006. The emergence of an ethical duty to disclose genetic research results: International perspectives. Eur J Hum Genet 14: $1170-1178$.

Knoppers BM, Deschênes M, Zawati MH, Tassé AM. 2012a. Population studies: Return of research results and incidental findings Policy Statement. Eur J Hum Genet 21: 245-247.

Knoppers BM, Zawati MH, Kirby ES. 2012b. Sampling populations of humans across the world: ELSI issues. Annu Rev Genom Hum Genet 13: 395-413.

Knoppers BM, Avard D, Sénécal K, Zawati MH. 2014a. P3G international paediatrics platform members. Return of whole-genome sequencing results in paediatric research: A statement of the P3G international paediatrics platform. Eur J Hum Genet 22: 3-5.

Knoppers BM, Sénécal K, Borry P, Avard D. 2014b. Wholegenome sequencing in newborn screening programs. $\mathrm{Sci}$ Transl Med 6: $229 \mathrm{~cm} 2$.

Knoppers BM, Zawati MH, Sénécal K. 2015. Return of genetic testing results in the era of whole-genome sequencing. Nat Rev Genet 16: 553.

Kohane IS, Altman RB. 2005. Health-information altruists-A potentially critical resource. $N$ Engl J Med 353: 2074-2077.

OECD (Organization for Economic Co-operation and Development). 2009. Guidelines on human biobanks and genetic research databases. oecd.org/sti/biotech/ 44054609.pdf.
Presidential Commission for the Study of Bioethical Issues. 2013. Anticipate and communicate: Ethical management of incidental and secondary findings in the clinical, research, and direct-to-consumer contexts. bioethics.gov/ node/ 3183 .

RMGA. 2016. Consolidated statement of principles. Network of Applied Medical Genetics, Quebec, Canada.

Rothstein M. 2012. Disclosing decedents' research results to relatives violates the HIPPA Privacy Rules. Am J Bioeth 12: $16-17$.

Schofield PN, Eppig J, Huala E, de Angelis MH, Harvey M, Davidson D, Weaver T, Brown S, Smedley D, Rosenthal N et al. 2010. Sustaining the data and bioresource commons. Science 330: 592-593.

Steven A, De Leonibus C, Hanson D, Whatmore A, Murray P, Donn R, Meyer S, Chatelain P, Clayton P. 2013. Pediatric perspective on pharmacogenomics. Pharmacogenomics J 14: 1889-1905.

Tabor HK, Berkman BE, Hull SC, Bamshad MJ. 2011. Genomics really gets personal: How exome and whole genome sequencing challenge the ethical framework of human genetics research. Am J Med Genet 155A: 29162924.

Tassé AM. 2011. The return of results of deceased research participants. J Law Med Ethics 39: 621-630.

UNESCO (United Nations Educational, Scientific and Cultural Organization). 2003. International declaration on human genetic data. Paris, France.

UNESCO. 2005. Universal declaration on bioethics and human rights. Paris, France.

Van El CG, Cornel MC, Borry P, Hastings RJ, Fellmann F Hodgson SV, Howard HC, Cambon-Thomsen A, Knoppers BM, Meijers-Heijboer H, et al. 2013. Whole-genome sequencing in health care: Recommendations of the European Society of Human Genetics. Eur J Hum Genet 21: S1-S5.

WHO. 2003. Genetic databases assessing the benefits and the impact on human and patient rights. World Health Organization, Geneva, Switzerland.

WMA (World Medical Association). 2002. WMA declaration on ethical considerations regarding health databases. October 2002. wma.net/en/30publications/10policies/ $\mathrm{d} 1 /$.

WMA. 2006. WMA international code of medical ethics. October 1949, with later amendations. wma.net/en/ 30publications/10policies/c8/.

WMA. 2013. WMA Declaration of Helsinki-Ethical principles for medical research involving human subjects. June 1964, with later amendations. wma.net/en/30 publications/10policies/b3/.

Wolf SM, Lawrenz FP, Nelson CA, Kahn JP, Cho MK, Clayton EW, Fletcher JG, Georgieff MK, Hammerschmidt D, Hudson K, et al. 2008. Managing incidental findings in human subjects research: Analysis and recommendations. J Law Med Ethics 3: 219-248.

Zawati MH, Parry D, Thorogood A, Nguyen MT, Boycott KM, Rosenblatt D, Knoppers BM. 2014. Reporting results from whole-genome and whole-exome sequencing in clinical practice: A proposal for Canada? J Med Genet 51: $68-70$ 


\section{$\&_{\mathrm{CSH}}^{\infty} \&$ Cold Spring Harbor

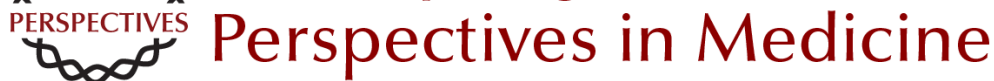

\section{Next-Generation Sequencing and the Return of Results}

Bartha Maria Knoppers, Minh Thu Nguyen, Karine Sénécal, Anne Marie Tassé and Ma'n H. Zawati

Cold Spring Harb Perspect Med 2016; doi: 10.1101/cshperspect.a026724 originally published online September 6, 2016

\section{Subject Collection Next-Generation Sequencing in Medicine}

Next-Generation Sequencing Technologies W. Richard McCombie, John D. McPherson and Elaine R. Mardis

The Impact of Next-Generation Sequencing on Cancer Genomics: From Discovery to Clinic Elaine R. Mardis

Next-Generation Sequencing in Autism Spectrum Disorder Stephan J. Sanders

Sequencing in High Definition Drives a Changing Worldview of the Epigenome Emily Hodges

Whole-Genome Sequencing in Cancer Eric Y. Zhao, Martin Jones and Steven J.M. Jones

\section{High Throughput Sequencing and Assessing} Disease Risk

Shannon M. Rego and Michael P. Snyder

Clinical Versus Research Sequencing Yuriy Shevchenko and Sherri Bale

\author{
Single-Cell Applications of Next-Generation \\ Sequencing \\ Naishitha Anaparthy, Yu-Jui Ho, Luciano \\ Martelotto, et al.
}

Future Promises and Concerns of Ubiquitous Next-Generation Sequencing W. Richard McCombie and John D. McPherson

Next-Generation Sequencing Strategies Shawn E. Levy and Braden E. Boone

\section{Characterizing the Cancer Genome in Blood} Sarah-Jane Dawson

The Role of Next-Generation Sequencing in Pharmacogenetics and Pharmacogenomics Ute I. Schwarz, Markus Gulilat and Richard B. Kim

The Use of Next-Generation Sequencing for Research and Diagnostics for Intellectual Disability Ricardo Harripaul, Abdul Noor, Muhammad Ayub, et al.

Next-Generation Sequencing and the Return of Results Bartha Maria Knoppers, Minh Thu Nguyen, Karine Sénécal, et al.

For additional articles in this collection, see http://perspectivesinmedicine.cshlp.org/cgi/collection/ 